\title{
CUANDO EL TEATRO ES NECESARIO: LOS NUEVOS FORMATOS TEATRALES UNA DÉCADA DESPUÉS (2009-2019)
}

\author{
WHEN THEATRE IS NEEDED: NEW THEATRE FORMS \\ TEN YEARS LATER (2009-2019)
}

\section{Cristina OÑORO OTERO}

Universidad Complutense de Madrid

crisonor@ucm.es

Resumen: Pasados diez años desde su eclosión, parece necesario reflexionar sobre lo que supusieron los Nuevos Formatos teatrales en la escena independiente de Madrid. En las páginas siguientes estudiaremos tres formatos distintos el Microteatro, el Teatro inmersivo (La Casa de la Portera) y el Teatro en Serie atendiendo al contexto en el que aparecieron fuertemente marcado por la crisis y sus recortes pero también a partir de un análisis de sus poéticas teatrales. Prestaremos especial atención al Teatro en Serie y a la herencia dejada por los Nuevos Formatos en el teatro español de comienzos del siglo XXI.

Palabras clave: Nuevos Formatos teatrales. Teatro y crisis. Teatro siglo XXI. Teatro independiente de Madrid.

\begin{abstract}
Ten years after its emergence, it is now time to reflect on what New Theatre Forms brought to the independent theatre landscape in Madrid. This article analyses three distinctive theatrical forms Microtheatre, Immersive Theatre (La Casa de la Portera) and Theatre Series in relation to both their context of origin characterised by the financial crisis and austerity cuts and the theatre theories behind them. This article aims to focus, in particular, in the Theatre Series and the legacy of these New Theatre Forms in early 21 st-century Spanish theatre.
\end{abstract}


Key Words: New Theatre Forms. Theatre and Crisis. 21st-century Theatre. Independent Theatre in Madrid.

\section{A MODO DE INTRODUCCIÓN}

Siempre es el teatro popular el que salva a una época. A través de los siglos ha adoptado muchas formas, con un único factor común: la tosquedad. Sal, sudor, ruido, olor: el teatro que no está en el teatro, el teatro en carretas, en carromatos, en tablados, con el público que permanece en pie, bebiendo, sentado alrededor de las mesas de la taberna, incorporado a la representación, respondiendo a los actores; el teatro en cuartos traseros, en falsas, en graneros; el teatro de una sola representación, con su rota cortina sujeta con alfileres a través de la sala, y otra, también rasgada, para ocultar los rápidos cambios de traje de los actores. Este término genérico, "teatro", abarca todo lo anterior así como las resplandecientes arañas (Brook, 2012: 93).

Esta descripción que realiza Peter Brook del teatro popular bien podría haberse aplicado a los Nuevos Formatos teatrales que surgieron en Madrid en torno al año 2009. El Microteatro, el Teatro en Serie o el Teatro inmersivo que se realizaba en espacios escénicos no convencionales como La Casa de la Portera también salvaron una época. Si atendemos al eco mediático que recibieron estas nuevas formas de teatro tosco en su momento, sobre todo en publicaciones nacionales como El País o Eldiario.es, pero también internacionales, como The Guardian y Théâtre/Public, la capital española fue testigo de un "milagro teatral en pequeño formato" (Molina, 2013; Tremlett, 2013) o, como llegaron a señalar algunos críticos, una auténtica "primavera de los teatros" (Peiró, 2013). En efecto, este teatro en cuartos traseros a domicilio, en viejos prostíbulos, en librerías, en espacios minúsculos, casi claustrofóbicos, o en una vieja portería reformada fue una respuesta milagrosa no solo ante la crisis económica y sus recortes sino también ante las limitaciones propias del teatro institucional y comercial para hacer un teatro verdaderamente vivo. Como podía leerse en sus páginas web -auténticos manifiestos artísticos- los Nuevos Formatos teatrales trataron de ofrecer al espectador una experiencia única y, quizás 
sin proponérselo conscientemente, fueron también uno de los primeros síntomas culturales de los cambios sociales y políticos que se expresarían, a partir de 2011, en movimientos sociales como el 15M (Boehm, 2018).

Ha pasado ya una década desde la creación de Microteatro por Dinero. A lo largo de estos años, numerosas salas de pequeño formato han abierto sus puertas y han cosechado el cálido reconocimiento tanto del público como de la crítica (Ordóñez, 2014). A pesar de ello, muchas se han visto obligadas a cerrar al poco tiempo, desmoralizadas por los numerosos obstáculos económicos e institucionales a los que debían hacer frente (Lillo, 2014).

Pasados ya diez años de su eclosión, hoy nos parece necesario reflexionar sobre lo que supusieron los Nuevos Formatos en la escena teatral independiente de la época. Sus propuestas que se multiplicaban a la misma velocidad que desparecían dan cuenta de una atmósfera cultural en mutación, al tiempo que nos obligan a pensar el hecho teatral desde nuevas perspectivas. ¿Qué formas de teatralidad -podemos preguntarnosgerminaron en estos espacios poco convencionales? ¿Qué conexión existió entre los Nuevos Formatos y los cambios económicos y políticos sucedidos durante esos mismos años? ¿Qué comunidades teatrales nacieron de aquellas maneras de estar juntos, casi pegados, en espacios tan reducidos? ¿A qué poética teatral, en definitiva, respondieron los llamados Nuevos Formatos?

En las páginas siguientes abordaremos estas cuestiones. Para ello, tomaremos en cuenta tres formatos distintos surgidos en Madrid entre 2009 y 2012 el Microteatro, el Teatro inmersivo (La Casa de la Portera) y el Teatro en Serie y dividiremos este artículo en cuatro apartados. En un primer momento, revisaremos el contexto en el que aparecieron, marcado por la crisis económica, las políticas de austeridad y los recortes; en segundo lugar, analizaremos qué rasgos tenían en común los tres formatos, prestando especial atención a la relación establecida entre actores y espectadores en estos espacios escénicos poco convencionales. A continuación, estudiaremos con más detalle un ejemplo concreto, el Teatro en Serie, atendiendo a sus características particulares, como sería la influencia de las series de televisión. Por último, realizaremos un breve balance sobre cuál podría ser la herencia que dejaron los Nuevos Formatos en la escena madrileña. 


\section{UN MILAGRO TEATRAL EN PEQUEÑO FORMATO}

Microteatro por Dinero surgió en noviembre de 2009. Siguiendo a Luis López de Arriba, la apertura de esta multisala suele considerarse el detonante de otros muchos formatos que revolucionaron "la manera de hacer y de ver teatro en nuestro país" (López de Arriba, 2017). Detrás de esta iniciativa se encontraba Miguel Alcantud, autor de la idea y coordinador del proyecto. Junto a él, casi cincuenta artistas presentaron un proyecto teatral en un antiguo prostíbulo situado en el número 4 de la calle Ballesta de Madrid. Tal y como leemos en la página web del proyecto', las trece habitaciones del antiguo burdel fueron ocupadas por trece grupos independientes con la consigna de crear una obra sobre un tema común -la prostitución- que no sobrepasara diez minutos y que estuviera dirigida a un público inferior a diez personas. Durante las dos semanas que duró el experimento - las obras se representaron entre el 13 y el 23 de noviembre tantas veces como hubiera espectadores-la afluencia de público fue enorme, lo que animó a sus fundadores a abrir el espacio de forma permanente en un local de la calle Loreto y Chicote, y a ir proponiendo nuevas temáticas como, por ejemplo, "por la familia", "por amor", "por ellas"...

Dos años y cuatro meses más tarde -el 8 de marzo de 2012- se abría La Casa de la Portera, situada en el piso bajo del número 24 de la Calle Abades de Madrid. De nuevo se trataba de un espacio muy poco convencional, pues esta casa de apenas cien metros cuadrados rehabilitada por José Martret y Alberto Puraenvidia era el lugar en el que, durante años, vivió la portera del edificio. El local se inauguró con la representación de Iván-Off, una versión actualizada de la obra de Chejov, dirigida por el propio Martret y calificada por él mismo como "teatro inmersivo", en la que nueve actores se dirigieron a un público de veintidós personas situado en dos habitaciones ambientadas para la ocasión. La Casa de la Portera acogió numerosos proyectos, pues distintos actores, pintores, músicos,

\footnotetext{
${ }^{1}$ Cf. https://microteatro.es/ [20/05/2019].

${ }^{2}$ Tras el éxito cosechado en Madrid, Microteatro abrió nuevas salas también en otras ciudades, tanto dentro como fuera de España, como Barcelona, Málaga, Buenos Aires, Veracruz o Miami, lo que confirma el éxito de la fórmula. En todo caso, el formato de la microobra ya había sido explorado por dramaturgos como, por ejemplo, Alfonso Zurro, quien, en 2010 también realizó experiencias de microteatro en las habitaciones del hotel Casa Romana de Sevilla.
} 
escenógrafos y otros muchos tipos de artistas leemos en su web tomaron la casa y la convirtieron en un espacio polivalente dedicado a la creación artística $^{3}$.

Pocos meses más tarde, en septiembre de 2012, veía la luz el primer capítulo de Días como estos, la primera obra de la compañía Teatro en Serie ${ }^{4}$. El espacio escogido en esta ocasión -la librería La Buena Vida, propiedad de los hermanos Trueba, situada en el barrio de Ópera de Madrid- seguía sin ser convencional, aunque no era tan extravagante como en las experiencias anteriormente mencionadas; no obstante, el formato era también muy innovador y novedoso: como si fuera una serie televisiva, la obra se componía de distintos capítulos que se irían representando a lo largo de los meses siguientes. El dramaturgo, Luis López de Arriba, era también el director de la obra, en la que actuaban cinco actores y en la que destacaba la economía de medios: una mesa, un teléfono y los libros de la propia librería constituían el único atrezo que los espectadores veían desde sus asientos, unas sillas plegables colocadas junto a las estanterías.

Como señalaba Javier Molina en un reportaje aparecido en El País Semanal, es innegable que la crisis fue el contexto socio-económico en el que nacieron estos Nuevos Formatos. Sin duda, los recortes en cultura, la

\footnotetext{
${ }^{3}$ La excelente acogida de La Casa de la Portera por parte de la crítica movió a sus creadores, Martret y Puraenvidia, a abrir otro espacio en noviembre de 2013, La Pensión de las Pulgas, donde desarrollaron propuestas semejantes. En todo caso, el fenómeno de las casas teatro no es exclusivamente español. Especialmente conocido es el caso de Argentina, que también vio renacer su manera de hacer teatro al calor de una crisis, la de 2001; no olvidemos que en 2005 el argentino Claudio Tolcachir convirtió su casa en un teatro, Timbre 4, y en sede de su propia compañía.

${ }^{4}$ A día de hoy, la obra se encuentra inédita, por lo que agradecemos al autor que nos haya facilitado el manuscrito para la redacción de este artículo. Lo que sí se encuentra disponible es una grabación del espectáculo en el Centro de Documentación Teatral de Madrid. Cf. http://teatro.es/ [20/05/2019].

${ }^{5} \mathrm{Al}$ igual que el Microteatro y el Teatro inmersivo, el Teatro en Serie pronto se convirtió en un fenómeno en expansión. Tanto es así que los teatros convencionales también apostaron por la fórmula. El Teatre Lliure de Barcelona, por ejemplo, incluyó en su programación de 2013-2014 Una sèrie de teatre, de Jordi Casanovas, un espectáculo serializado que fue estrenando los capítulos entre los meses de abril y mayo de 2014. Ese mismo año, el Teatro Echegaray de Málaga estrenó Nightshot, de Paco Bernal y Nacho Albert, también una obra de teatro en capítulos. Para un recorrido por los distintos espectáculos de teatro serializado tanto en España como fuera de nuestro país, véase López de Arriba (2017).
} 
subida del IVA al 21\% decretada por el Gobierno en septiembre de 2012, que ocasionó la pérdida de un $31,43 \%$ de espectadores con respecto al año anterior, o el cierre de numerosas salas, como el teatro Albéniz, son elementos que hay que tener en cuenta para comprender su gestación (cfr. Molina, 2013).

En todo caso, la situación económica no fue, ni mucho menos, el único factor que explica el nacimiento de los Nuevos Formatos. Conviene recordar que, antes de la crisis, muchos grupos alternativos madrileños la mayoría no recibían subvenciones estatales ni tenían posibilidad de estrenar en salas comerciales. Así, cuando a Luis López de Arriba le preguntaron si creía que la crisis estaba en el origen de las nuevas propuestas, su respuesta fue contundente: "No; es lo que los medios han querido vender pero no es así. Es una respuesta al mal endémico del teatro en este país, consistente en una mala gestión pública y privada de la distribución de los espectáculos teatrales". Se trata de una opinión semejante a la que sostenían Miguel Alcantud y José Martret en un encuentro en torno a los Nuevos Formatos organizado en la librería La Buena Vida y moderado por el propio López de Arriba el 26 de abril de 2013. Ambos directores insistieron en que la apertura de sus locales no respondía tanto a la crisis como a una necesidad vital de trabajar sin llamar a ninguna puerta. Por eso los dos decidieron crear su propio teatro. Las palabras de José Martret fueron especialmente elocuentes: "no nos encontrábamos más que puertas cerradas. Estábamos hartos de que todo fueran noes" (citado en López de Arriba, 2017).

Cuatro años más tarde, el propio López de Arriba reflexionaba a propósito de las declaraciones de Martret, reconociendo la profunda verdad que escondían:

en el comienzo del siglo XXI ni los teatros comerciales ni las propias salas alternativas, circuito off o cualquier término que se les quiera dar, eran suficientes para acoger el trabajo de los creadores, que veían como dichas salas, que surgen en los años 80 para acoger las propuestas más rompedoras, se han vuelto tan herméticas o imposibles para muchas compañias teatrales que se ven obligadas

\footnotetext{
${ }^{6}$ Estas declaraciones así como otras que también citaremos a lo largo de estas páginas proceden de una entrevista inédita, realizada específicamente para la redacción de este artículo.
} 
a emprender un nuevo rumbo (López de Arriba, 2017).

¿En qué momento - podemos preguntarnos- empezaron los jóvenes creadores a sentir que la escena alternativa era tan hermética e inaccesible como el teatro comercial e institucional? ¿A qué mal endémico se refería López de Arriba como verdadero detonante del nacimiento de los Nuevos Formatos? Merece la pena que nos detengamos unos instantes en la historia de nuestro teatro alternativo para contextualizar las palabras de Martret y López de Arriba.

Aunque la existencia de un teatro no comercial en España es anterior a la Guerra Civil, la expresión teatro independiente hace referencia a una serie de compañías concretas, de grupos independientes ${ }^{7}$, que aparecieron durante los años sesenta y setenta, como, por ejemplo, Goliardos, Ditirambo, Tábano, Teatro libre o también el TEI (Teatro Experimental Independiente). Estas compañías, que tenían como antecedente los grupos de teatro no profesional que emergieron a partir de los años cincuenta (Santolaria, 1997), trataban de desmarcarse del teatro oficial y comercial considerado como dependiente - desde un punto de vista económico, político y estético- de la dictadura franquista (Cornago Bernal, 1999).

Según Antonio Fernández Insuela, las características fundacionales de este teatro independiente español son, por una parte, la renovación estética y dramatúrgica (alejamiento del teatro de texto, desacralización del autor, experimentación con técnicas de improvisación y de creación colectiva, indagación sobre nuevos lenguajes escénicos o trabajo de la expresión corporal, entre otros) y, por otra, la búsqueda de nuevos públicos, especialmente espectadores que no procedieran de las clases burguesas afines al franquismo. A estas dos características habría que sumar su ideología política: estos grupos hacían un teatro crítico con la España de la dictadura, al tiempo que plantearon nuevas formas de organización, basadas en el colectivismo (modelo de autogestión, rechazo del protagonismo de ciertos actores o dramaturgos, modos de producción igualitaria...). En definitiva, como apunta Alonso de Santos, estas compañías independientes buscaban una alternativa vital, cultural, política y profesional (Alonso de

\footnotetext{
${ }^{7}$ Según José Luis Alonso de Santos, el teatro independiente español probablemente toma su nombre del teatro independiente argentino de los años $50 \mathrm{y}$ de los movimientos underground norteamericanos de la misma época.
} 
Santos, 1989).

Con la llegada de la democracia a finales de los años setenta, puede constatarse cierta desorientación entre los grupos de teatro independiente. El número de espectadores bajó considerablemente, entre otras razones porque, como explica Alonso de Santos (1989), el público dejó de percibir el teatro como un instrumento de contestación política. Algunos grupos desaparecieron (Tábano, Goliardos, TEI, Teatro Libre...) o tomaron otros rumbos (Joglars, La Cuadra, Comediants...). Posteriormente, desde finales de los años ochenta, se produjo lo que podemos llamar la oficialización del teatro independiente $\mathrm{y}$, en consecuencia, la pérdida de dicha independencia. A partir de ese momento, si querían recibir apoyos y subvenciones de las instituciones públicas, los grupos debían plegarse a ciertas exigencias. La administración pasó a convertirse en el nuevo empresario, lo que para Alonso de Santos significó, precisamente, el fin de la independencia.

Cuando la crisis económica estalló en España en el año 2008 el contexto de la creación teatral se encontraba muy polarizado. Por un lado, existían algunas compañías y creadores que recibían subvenciones públicas y apoyos, pero, por otro, una gran cantidad de jóvenes artistas no terminaban de abrirse camino ni de lograr acceso a dichos apoyos y subvenciones. Sin duda, había espacios para el teatro alternativo - pensemos en Cuarta Pared, Pradillo, Triángulo, Mirador, Replika Teatro, por nombrar solo algunas salas representativas de Madrid-pero numerosos creadores se quedaban sin poder mostrar en ellas su trabajo. De este modo, el efecto de la crisis en las artes escénicas fue, hasta cierto punto, paradójico: para unos supuso el drástico recorte de apoyos y recursos, pero, para otros, como Alcantud, Martret o López de Arriba, se abrió una ventana de oportunidad, un escenario creativo menos hermético e inaccesible. Veamos en qué sentido.

Las compañías que recibían subvenciones y contratos de la administración (estatal, autonómica o municipal) fueron las principales perjudicadas porque fueron ellas las que tuvieron que encajar el duro golpe de las políticas de austeridad: los recortes en los presupuestos municipales supusieron el descenso del $60 \%$ de los contratos municipales para representaciones teatrales, el cierre de salas, la desaparición de festivales y la suspensión de giras. Medidas a la que hay que sumar otra de las más polémicas: el ya mencionado aumento del IVA del 8 al 21\% en 2012, con el consiguiente incremento del precio de la entrada (García, 2013). 
Ir al teatro pasó a ser un bien de lujo justamente en el momento en que las familias españolas debían hacer frente a la bajada de salarios y el aumento del paro. Solo en los meses siguientes a la subida del IVA, el teatro perdió 1,8 millones de espectadores respecto al año anterior, 600 puestos de trabajo y los beneficios generados por el sector disminuyeron un 33\% (García, 2013).

Sin embargo, si prestamos atención a la cantidad de proyectos como Microteatro o La Casa de la Portera que pudieron ponerse en marcha en aquellos mismos años, el teatro alternativo madrileño no solo no se hundió sino que vivió una verdadera primavera. A diferencia de aquellas compañías que dependían directamente del dinero público, creadores como Alcantud, Martret o López de Arriba, entre otros muchos, encontraron en la nueva coyuntura un contexto más propicio para inventar nuevas formas de ver y hacer teatro. Así, durante los años siguientes al estallido de la crisis, la oferta de propuestas originales creció como la espuma. A poco que naveguemos en internet -espacio donde solían difundirse- los ejemplos de representaciones en espacios domésticos o poco convencionales se multiplicaron entre 2009 y 2016. Tanto es así que, en 2015, fecha en la que probablemente alcanzaron mayor popularidad, la periodista Paula Corroto llegó a elevar a ciento cincuenta las salas de pequeño formato que tenían abiertas las puertas solo en Madrid. Hacía años, en definitiva, que la escena alternativa no era tan dinámica; en espacios muy poco convencionales -casas, tiendas, azoteas, cárceles, peluquerías, viejos prostíbulos, porterías- proliferaban todo tipo de propuestas, cada una más original: teatro inmersivo, deambulatorio, micro-teatro, teatro en serie, ficciones sonoras.... (Fernández Santos, 2013).

Pero, podemos preguntarnos, esta explosión de creatividad ¿fue positiva o negativa para el teatro independiente? ¿Condenó a los jóvenes al pequeño formato -el low cost teatral- o sirvió como acicate? ¿Reflejó la precariedad o ayudó a combatirla? No es sencillo responder a estas preguntas. En todo caso, en el último apartado volveremos sobre la herencia que han dejado los Nuevos Formatos, para así poder valorar, diez años después, lo que pudieron aportar al teatro español de comienzos del siglo XXI.

Pasemos ahora a analizar qué características compartían los tres formatos que hemos escogido así como sus principales diferencias y similitudes. 


\section{HACIA UNA POÉTICA DE LOS NUEVOS FORMATOS}

La insistencia en la novedad del formato es el primer rasgo que comparten el Microteatro, el Teatro inmersivo y el Teatro en Serie. En los tres casos el proyecto teatral se presentaba como una experiencia inédita e innovadora: "Nuevo concepto de formato teatral", "Nuevo concepto de espacio escénico", "Nueva forma de contar historias y de aproximar al espectador" son el tipo de descripciones que encontramos en sus páginas de internet. Sin restarle originalidad a las nuevas propuestas, conviene recordar que la historia del teatro en espacios alternativos, pequeños o domésticos en realidad es muy antigua. Así, pueden citarse los pequeños locales del Off-Brodway neoyorquino, en los años cincuenta del siglo pasado, donde podían verse espectáculos modestos en comparación con los grandes teatros de la ciudad; o ciertas experiencias tanto de las vanguardias como del teatro-performance contemporáneo, referente histórico en lo que a la ruptura de la distancia entre actores y espectadores se refiere (Danan, 2013). Por otro lado, habría que mencionar la existencia en nuestro país del género chico, especialmente del llamado teatro por horas, que surgió a finales del siglo diecinueve y con el que culminó la rica tradición española del teatro breve. Al igual que los Nuevos Formatos, estos espectáculos de corta duración con gran éxito entre la gente también se representaban en cafés-teatro y otros espacios humildes ${ }^{8}$.

Tanto a los Nuevos Formatos como a estos ejemplos mencionados cabría pues aplicarles esta otra descripción que hace Peter Brook del teatro popular:

Es la celebración de todo tipo de "medios disponibles" y lleva consigo la destrucción de todo lo que tiene que ver con la estética. Esto no significa que no haya también belleza. "Toscos" son los que dicen: "No tenemos medios externos, ni un céntimo, ni habilidad, ni conocimientos estéticos, no podemos pagarnos hermosos trajes ni

\footnotetext{
${ }^{8}$ Véase el volumen dirigido por Javier Huerta Calvo, Historia del teatro breve en España (2008), especialmente el capítulo dedicado al "Arte escénico" del siglo XX, a cargo de Eduardo Pérez Rasilla (2008), donde encontramos un apartado sobre el "Teatro por horas".
} 
decorados, no tenemos escenario, ni otra cosa que no sean nuestros cuerpos, nuestra imaginación y lo que tengamos a mano" (Brook, 2010: 76).

A la vista de tantos antecedentes, podría parecer que la etiqueta Nuevos Formatos escondía ya desde el comienzo una doble trampa: ni serían nuevos, ni la cuestión del formato tendría excesiva relevancia, pues las formas -nos recuerda Peter Brook en otro ensayo (2010: 110)-suelen llevar inscrita su fecha de caducidad. No obstante, este peligroso razonamiento -no hay nada nuevo, nadie inventa nada- nos impediría reconocer en estos fenómenos teatrales verdaderos focos de resistencia en un país al que las políticas de austeridad y los recortes estaban estrangulando económica y socialmente. Así los caracterizaba el teórico teatral Olivier Neveux en una intervención en la Universidad de Estrasburgo sobre el teatro en época de crisis y describía estos milagros teatrales en pequeño formato como espacios de luz en época de tinieblas ${ }^{9}$. En este sentido, quizás los Nuevos Formatos no fueran nuevos, pero es muy revelador que necesitasen presentarse así y fueran aceptados por el público como tales. Quizás, lo que sí fue nuevo y sí fue fruto de la crisis fue la necesidad imperante de la sociedad española de entonces de encontrar espacios alternativos en los que otra manera de estar juntos y crear comunidad adquiriera significado (Cameron, 2014; Feinberg, 2014).

El segundo rasgo que unía las tres propuestas ya ha sido mencionado. Nos referimos a la utilización de lugares poco convencionales para una representación, como son un prostíbulo, una portería y una librería. ¿Qué distinguiría este uso que hicieron del espacio - podemos preguntarnos- de tantos otros espectáculos que, desde siempre, también se han realizado en espacios alternativos? Aunque las fronteras no son siempre nítidas, podemos responder que los espectáculos de los Nuevos Formatos no solo se representaron en espacios poco convencionales sino que nacieron con y para ellos. Se trata, por tanto, de prácticas teatrales site-specific, es decir,

\footnotetext{
9 “Intervenir dans la crise. Le théâtre politique à l'heure de la crise", seminario organizado por el equipo de investigación C.H.E.R. (Culture et Histoire dans l'Espace Roman) el 8 de noviembre de 2013 en el marco del programa "Hybris et catastrophe: les arts de la scène en Europe face à la crise" en la Maison Interuniversitaire des Sciences de l'HommeAlsace (Universidad de Estrasburgo).
} 
concebidas para lugares concretos y poco convencionales (Pearson, 2010). De hecho, López de Arriba consideraba que fue esta vinculación a nuevos espacios lo que verdaderamente singularizó a los Nuevos Formatos y los convirtió en un nuevo modo de producir y distribuir teatro ${ }^{10}$.

En relación con esto último podemos mencionar un tercer rasgo, a saber, el tamaño extremadamente reducido del espacio teatral. En efecto, las habitaciones donde se representa Microteatro apenas cuentan con quince metros cuadrados, La Casa de la Portera solo tenía cien y la librería La Buena Vida, donde se realizó el primer espectáculo de Teatro en Serie, emplazaba la representación en un pequeño espacio entre sus estantes de libros. En conexión directa con esta limitación espacial es necesario mencionar la duración de las representaciones, pues en la mayoría de las representaciones también destacaba la brevedad. Solo una hora en el caso del Teatro en Serie - como un programa de televisión- y no más de quince minutos en el caso del Microteatro. En estos dos ejemplos la cuestión del tiempo es esencial y una de las marcas distintivas de ambos formatos ${ }^{11}$ : en el Microteatro, por ejemplo, se representan varias obras simultáneamente, por lo que es el espectador quien decide cuánto tiempo quiere estar en el teatro -a cuántas representaciones quiere asistir- $\mathrm{y}$ cuánto dinero quiere gastarse. Y lo mismo ocurría en el Teatro en Serie: cuando estrenaban un capítulo nuevo, también reponían los anteriores, por lo que también era el espectador quien decidía cuántos capítulos quería ver esa tarde o si prefería volver al día siguiente para asistir al que le faltaba...

No cabe duda de que el factor tiempo -y su flexibilidad- fue una de las claves del éxito de estos formatos populares, pues les permitió conectar con todo tipo de gente, incluso con personas que en principio no irían al teatro. En este aspecto, la brevedad contrastaría con la larga duración de espectáculos contemporáneos, como serían los montajes de Krystian Lupa, Robert Wilson o Robert Lepage, habitualmente en cartel en la capital española. Por otro lado, esta dicotomía larga / corta duración también implicaría dos formas distintas de concentrarse y de prestar atención en el teatro: mientras que los espectáculos de los grandes directores de escena mencionados requieren un trabajo de atención plena, las experiencias que,

\footnotetext{
${ }^{10}$ Ver nota 8.

${ }^{11}$ Este rasgo no podría aplicarse a La Casa de la Portera, pues espectáculos como el IvánOff, por ejemplo, tienen una duración de dos horas.
} 
por ejemplo, se proponen en el Microteatro se caracterizarían, en cambio, por la brevedad de los estímulos -no más de quince minutos-pero también por su multiplicidad, ya que el espectador puede acudir hasta a quince representaciones en una misma tarde ${ }^{12}$.

La insistencia en la novedad, el uso de lugares poco convencionales y la condensación espacio-temporal de la representación no son las únicas características comunes de los Nuevos Formatos. Hemos de señalar también el éxito de público, el dinamismo de la programación, el precio reducido de la entrada así como el uso de las redes sociales y unas atractivas páginas web para la difusión y publicidad de los espectáculos. Por último, en el caso del Microteatro y el Teatro en Serie destaca también la existencia de un bar en el local de la representación, lo que reforzaría el carácter popular de estas propuestas. Estas últimas características fueron, sin duda, esenciales para atraer nuevos públicos, sobre todo a los más jóvenes, quienes, durante los años más duros de la crisis económica, se vieron especialmente castigados por la precariedad laboral, los recortes en educación y la subida de las tasas universitarias. Esta capacidad para conectar con un público joven hablando su mismo lenguaje se refleja elocuentemente en el modo en que Miguel Alcantud llegó a autodenominar el Microteatro: "el youtube del teatro" (citado en López de Arriba, 2017).

Antes de pasar al siguiente apartado resulta pertinente abordar un último rasgo que compartían los tres formatos. Se trata de a la voluntad que manifestaban todos ellos de integrar al espectador en la representación con la voluntad de ofrecerle una experiencia que a menudo calificaban como inmersiva. Se trata de un aspecto que, precisamente, López de Arriba señalaba a la hora de establecer una poética común de las nuevas propuestas: "la proximidad del público, el hecho de que la experiencia teatral sea diferente, más cercana, más palpable y sin trampa ni cartón: actuación en estado puro. Es su virtud y su peligro"13.

Como señala Hans-Thies Lehmann (2012) en un artículo sobre el estatuto del espectador contemporáneo, parece que el empleo de cierta retórica performativa se haya vuelto imprescindible para conectar con el

\footnotetext{
${ }^{12}$ En un artículo revelador, N. Katherine Hayles denomina Hyper y Deep Attention a estas dos maneras distintas de concentrarse. Para una caracterización de ambas, véase Hayles (2007: 187).

${ }^{13}$ Ver nota 9.
} 
público actual. Así, como apunta también Erika Fischer-Lichte, la influencia del giro performativo en todas las artes - no solo las plásticas-desde los años sesenta explicaría la tendencia de los artistas contemporáneos a presentar sus producciones como "acontecimientos en los que están involucrados no solo ellos mismos, sino también los receptores, los observadores, los oyentes y los espectadores" (2011: 45). En este sentido, ciertas fórmulas empleadas por los Nuevos Formatos, como "nueva experiencia inmersiva" o "aproximar al espectador de manera no convencional", podrían parecer meros reclamos publicitarios que, siguiendo la moda, buscaron atraer a un público ávido de experiencias cada vez más reales.

Esta hipótesis vendría a confirmarse por el hecho de que ese gesto aparentemente performativo de convertir al espectador en piedra angular del espectáculo no se correspondería con el corte marcadamente ilusionista de muchas de las propuestas dramatúrgicas - con prioridad del texto, intriga, personajes definidos y puesta en escena uniforme- que pudieron verse en estos locales ${ }^{14}$. En el caso del Teatro en Serie o del Microteatro, por ejemplo, cabría preguntarse si realmente nos encontramos ante un espectáculo de interacción con el público, como en el arte de la performance o los happening, o más bien ante un teatro que solo suspende momentáneamente el pacto de ficción -a través de monólogos o preguntas al público-para enseguida volver a reclamar su identificación con el cosmos dramático ${ }^{15}$. El ilusionismo patente -"actuación en estado puro", recordemos que era la fórmula empleada por López de Arriba-y el valor semiótico de los objetos y los cuerpos puestos en escena serían otras características de los Nuevos Formatos que, a pesar de la retórica participativa a la que aludíamos, en principio los distanciarían de la performance, un arte que se caracteriza por el anti-ilusionismo y por tomar los objetos y cuerpos en escena en su valor material y no semiótico.

No obstante, tal vez tengamos que valorar el alcance performativo de estos espectáculos tomando en cuenta otros elementos. Me refiero a la importancia que tienen en los Nuevos Formatos el contacto físico entre

\footnotetext{
${ }^{14}$ Así, por ejemplo, en la página web de Microteatro leemos que "Las obras representadas contienen las características propias de una obra tradicional. Requieren un guion previo y una puesta en escena uniforme y permanente mientras se represente". Cf. https:// microteatro.es/ [20/05/2019].

${ }^{15}$ Se trata de una distinción que Hans-Thies Lehmann (2012) explora en el artículo mencionado.
} 
actores y espectadores y la voluntad de transformar a estos, en tanto que individuos, en una comunidad; como explica la propia Fischer-Lichte, estos rasgos también son constitutivos de la performance (2011: 105 y ss.). En este sentido, las dimensiones llamativamente reducidas del espacio teatral, la elección de lugares fuertemente enraizados en la realidad social -un prostíbulo, una portería y una librería- así como la importancia de la creación de una atmósfera envolvente que comienza desde el momento mismo en el que se traspasa la puerta de estos locales atestiguan el peso que poseen estos elementos - contacto y comunidad-en las nuevas propuestas.

En definitiva, los Nuevos Formatos no emplearon una retórica performativa hueca simplemente para atraer al público, sino que $3 / 4$ volviendo a la idea anterior sobre la necesidad de presentarse como espacios alternativos en los que negociar las relaciones sociales $3 / 4$, habrían heredado del arte de la performance la voluntad de redefinir radicalmente el concepto de comunidad. Como remarca López de Arriba al recordar el momento de las representaciones del Teatro en Serie: "Conseguimos crear un ambiente muy distendido, un micromundo que empezaba desde que la gente entraba en la librería, pedía su bebida, escuchaba la música y miraba libros. Siempre había ya algún actor en escena. Era la misma gente que luego rodeaba a los actores" 16 .

\section{NUEVAS FORMAS DE CONTAR HISTORIAS: EL TEATRO EN SERIE}

Tal y como aparece definido por Luis López de Arriba:

El teatro por capítulos [...] sigue la línea del teatro de cerca que ya estaba desarrollándose desde antes incluso de la aparición de la sala de Loreto y Chicote. Dentro de este término englobaríamos aquellas obras dramáticas divididas en capitulos y con una trama continua, con personajes que se repiten al menos en parte de los episodios y un criterio unitario que cohesione las distintas entregas de la obra. Dejamos fuera, por tanto, aquellas obras dramáticas que se puedan entender como trilogías o ciclos, desde el ciclo mítico de las Comedias Bárbaras de Valle-Inclán hasta la más reciente

16 Ver nota 8. 
Trilogía de la juventud, de José Ramón Fernández, Yolanda Pallín y Javier G. Yagüe (López de Arriba, 2017).

Siguiendo al propio López de Arriba, la primera obra por capítulos que, cumpliendo con estos criterios, vio la luz en España sería Teatro a pelo, estrenada en Sevilla en el hostal La Caja Habitada en febrero de 2012. El montaje se prolongó hasta 2015 a través de nueve capítulos, todos ellos de corta duración. Teatro a pelo, escrita por Julio León y dirigida por Francisco Pérez, logró mantenerse tres años en cartel y dio lugar a otras obras por capítulos firmadas por los mismos autores: La noche de las flores (galería de arte Slowtrack en Madrid, 2013), La compañía (Teatro Quintero, diciembre de 2015), Underground y Topos. Estas dos últimas eran series de tres capítulos producidas para Metro de Sevilla en 2014 y 2015.

En paralelo a Teatro a pelo, Días como estos, la primera obra de la compañía Teatro en Serie, se representó en la librería La Buena Vida de Madrid entre septiembre de 2012 y junio de 2013; el espectáculo en su conjunto se estructura en cuatro capítulos, cada uno de ellos de una duración de una hora aproximadamente; a su vez, cada capítulo, dividido en distintas escenas, forma parte de la serie, pero también posee unidad y coherencia en sí mismo. La acción se desarrolla a lo largo de un año y unos meses en una librería -llamada también La Buena Vida-, propiedad de Martín, el personaje protagonista, quien la heredó de su padre, fallecido recientemente. Además de Martín, hay tres personajes fundamentales -Ana, Alberto y Helena- así como un "multipersonaje", llevado a escena por un único actor, que representa los papeles de "madre", "adolescente", "ciego"... Como en muchas comedias televisivas, estos cuatro jóvenes en la treintena aparecen retratados de forma muy realista a partir de un lenguaje fresco y directo, lo que contribuye a que el espectador pueda identificarse con ellos fácilmente. El amor, la amistad y la memoria en días como estos son los temas que se abordan a partir del entramado de relaciones íntimas entre los personajes.

¿Qué rasgos dan singularidad al Teatro en Serie en el marco de las nuevas tendencias?

En primer lugar, podemos mencionar la continuidad entre el espacio dramático, el escénico y el teatral. En efecto, la librería La Buena Vida es, al mismo tiempo, un lugar de ficción, un escenario y un espacio teatral. 
En este sentido, y como ocurre con el "espacio-tablado" descrito por Anne Ubersfeld (1996: 57), la ruptura no se produce, como en un teatro a la italiana, entre el espectáculo y el espectador, sino entre el espacio teatral y el resto del mundo. Esta característica sin duda contribuye a acentuar la experiencia inmersiva a la que ya nos hemos referido antes. Así lo señala también López de Arriba: "en nuestra experiencia, al usar un espacio real, especialmente atractivo por la atmósfera de la librería, el espectador siente el espectáculo de otro modo, todo ocurre a su alrededor"17.

No obstante, el rasgo que sin duda distingue este formato del resto de propuestas es la influencia que ejercen sobre él las series de televisión. Enumeremos algunos de los mecanismos propios de este medio que López de Arriba asimila después al lenguaje teatral:

$\square$ Empleo de un hilo musical reconocible por el espectador tanto al inicio como al final del capítulo.

$\square$ Introducción de un breve resumen del capítulo anterior.

- Estructura dramática semejante a las series, basada en la preponderancia de la intriga y el esquematismo de los personajes.

$\square$ Construcción del argumento a partir de las relaciones establecidas por unos personajes en un único espacio dramático.

Existe además un cuarto mecanismo tomado de las series televisivas que por su originalidad dramatúrgica merece comentarse aparte. Me refiero al tratamiento que recibe el tiempo. Como es sabido, tanto en el cine como en la televisión las retrospecciones son un recurso muy común para abordar el pasado de la historia y los personajes, lo que permite al espectador audiovisual saltar en el tiempo sin problemas, una operación mucho más compleja en el caso de una obra de teatro. En este sentido, uno de los aspectos dramatúrgicos más originales de Días como estos es, precisamente, la trasposición al lenguaje teatral de los flashback televisivos. Veamos un ejemplo:

ANA. - Pensaba en cuando nos conocimos.

MARTÍN. - Un encuentro francamente curioso [...].

ANA.- [...] Vamos a recordar la situación.

MARTÍN. - No estoy seguro de que puedas recordar mucho.

17 Ver nota 8. 
ANA.- ¿Puedes ayudarme? (ELENA toma de la mano a un actor al que en adelante llamaremos MARTíN BIS). Bien, estamos en una discoteca. Imaginemos que estamos en una discoteca, tú eres Martín, yo estoy en la barra pidiendo una copa y tú estás, solo y amargado, mirándome...

MARTÍN BIS actúa lo que ANA le propone. [...] (López de Arriba, 2013: I, 28-29).

Como en nuestro ejemplo, en numerosas ocasiones a lo largo de la obra, los personajes interrumpen la acción en curso para presentar hechos que, ocurridos en un tiempo anterior, guardan relación con ella. Y lo interesante es el procedimiento del que se sirven para ello: como si fuera una representación, ponen en escena estas retrospecciones -las teatralizan- ante los ojos mismos del espectador. Para ello, normalmente solicitan la ayuda del multipersonaje, sentado entre el público como uno más, quien siempre se presta para encarnar los roles que haga falta. Este recurso se vuelve especialmente interesante cuando, como en el ejemplo citado, el actor-comodín hace de un personaje que ya está presente en escena, produciendo entonces su desdoblamiento y multiplicando los niveles de teatralidad de la obra.

Otro aspecto relevante a la hora de calibrar las similitudes y diferencias de las series de televisión y Teatro en Serie tiene que ver con el gran desafío que supone para este último la fidelización del espectador. Como recuerda Luis López de Arriba, los "giros de guion" o cliffhanger, inventados por los dramaturgos clásicos y teorizados por Aristóteles en la Poética, son un recurso habitual en el lenguaje del guion televisivo (en las telenovelas, la soap-opera o las sitcom) que pretende provocar en el espectador el deseo de ver el siguiente capítulo. Ahora bien, si lograr que un espectador televisivo vea el siguiente capítulo es relativamente sencillo (aunque depende, lógicamente, de si la serie se difunde en abierto o a través de canales de pago), conseguir que un espectador regrese al teatro, no una sino hasta cuatro veces por temporada, parece mucho más complicado. Por eso vuelve a ser esencial el coste moderado de la entrada así como la creación de expectativas en el espectador a través de giros de guion que susciten su curiosidad.

En todo caso, es indudable que el éxito y calidad actual de las series de televisión es un factor que favorece la fidelización del espectador del teatro en serie. Hasta cierto punto podemos decir que se traslada al teatro 
una práctica cultural como ver una serie que, sobre todo en los últimos tiempos, se ha vuelto habitual en países de todo el mundo. Como apunta Fernando Ángel Moreno en Yo soy más de series. "las series parecen haber tomado el protagonismo en nuestro mundo cultural como el teatro en el siglo XVII, la novela en el XIX [y] el cine a mediados del XX)" (Moreno, 2015: 13). Y es que, como comenta a su vez Dominique Moïsi en Geopolítica de las series, los mejores guionistas de hoy son comparables "a los grandes novelistas del pasado, desde Balzac hasta Flaubert, pasando por Dickens" (2017: 11). Para este autor, "las series no solo se han convertido en el equivalente de lo que fueron los folletines del siglo XIX: una dimensión esencial de la cultura", sino que sus creadores "se han convertido en los mejores analistas de las sociedades y del mundo actual, por no decir en los futurólogos más fiables" (2017: 11).

Otro elemento que sin duda favorece la fidelización del espectador tiene que ver con la duración temporal de la serie. Al igual que sucede en la televisión, donde "los personajes de las series, más que los de los libros y los de las películas, evolucionan a un ritmo parecido al nuestro, a lo largo de años y acompañándonos en nuestras conversaciones cotidianas" (Moreno, 2015: 13), lo mismo podemos decir que ocurre en el Teatro en Serie. El espectador regresa al teatro pasado el tiempo y, al hacerlo, su propia vida va evolucionando al ritmo que progresa la trama. A los personajes que suscitan su interés les habrán ocurrido, al igual que a él, cosas nuevas. Volver al teatro, como toda práctica ritual, es una manera de tomar conciencia, a partir de la repetición, de cómo vamos cambiando.

De hecho, según Dominique Moïsi, uno de los factores esenciales para comprender el éxito de las series de televisión es precisamente la relación especial con el tiempo que se genera:

El tiempo de la serie [...] se aproxima más al de la literatura que al del cine. [...] Con una media de doce episodios por temporada, la serie se convierte en "tiempo real". La espera del próximo capitulo -salvo para quienes ven las series en DVD o en streaming- es la causa del éxito de la serie [...]. Igual que en la vida, los personajes de la serie televisiva tienen, en cierta forma, "el tiempo del tiempo". [...] Como en la vida real, muchas historias se enmarañan, se suceden, se superponen. [...] Y, con el tiempo, el mundo real se insinúa en el mundo de la ficción (Moïsi, 2017: 47-48). 
Finalmente podríamos llamar la atención sobre un último aspecto del Teatro en Serie que es relevante para valorar lo que antes hemos denominado el alcance performativo de los Nuevos Formatos. Según la conocida fórmula de Erika Fischer-Lichte, una performance se crea a partir de un intercambio de energía - un bucle de retroalimentación- entre actores y espectadores. No cabe duda de que el Teatro en Serie no es una performance, pues ya hemos visto que se distancia de este arte por el ilusionismo y el valor semiótico de los objetos y cuerpos puestos en escena. Sin embargo, algunos de los elementos que lo constituyen como formato sí puede considerarse que proceden de este arte. A dos de ellos ya nos hemos referido -contacto y comunidad-, pero habría un tercero que estaría estrechamente relacionado con el funcionamiento del bucle de retroalimentación performativo. Veamos en qué sentido.

A lo largo de la obra existen distintos momentos en los que se interpela directamente a los espectadores o se solicita que participen. No obstante, como decíamos antes, este recurso ni rompe verdaderamente el pacto de ficción ni libera la representación a la contingencia de lo imprevisible, lo que es esencial en una performance. Por tanto, es en otro nivel donde hemos de ir a buscar el impacto performativo de ese intercambio de energía entre actores y espectadores al que se refiere Fischer-Lichte. Para explicarlo leamos la reflexión del propio López de Arriba a propósito del proceso dramatúrgico que siguió para escribir Días como estos:

\begin{abstract}
El primer capitulo fue mostrado en un ensayo con público para ver sus reacciones y me motivó incluso a cambiar el final. No escribi los demás hasta que fuimos estrenando. [...] Estrenaba un capitulo y escribia el siguiente $y$, entre medias, surgian nuevas ideas que iba reservando para los siguientes capítulos. [...] En conclusión, en este caso, el formato condicionó todo ${ }^{18}$.
\end{abstract}

Como vemos, el formato serializado propició que el intercambio de energía entre actores y espectadores tuviese un impacto real en la escritura de los siguientes capítulos, un fenómeno que sí transformó al público de Días como estos en participante activo del proceso creativo. Desde

18 Ver nota 8. 
este punto de vista, el Teatro en Serie representaría un buen ejemplo del dinámico intercambio que existe entre teatro y performance desde los años noventa (Fischer-Lichte, 2011: 100).

\section{EL LEGADO DE LOS NUEVOS FORMATOS TEATRALES: ENTRE LA PRECARIEDAD Y LA ESPERANZA}

A pesar del tiempo sucedido desde su eclosión, los Nuevos Formatos siguen siendo a día de hoy un fenómeno relativamente reciente en la historia de la escena teatral, tanto madrileña como española. Aunque es cierto que cada vez existen más estudios que los analizan, aún queda mucho camino por recorrer y, en este sentido, no solo es necesario contar con un margen temporal más dilatado para poder establecer conclusiones sino que también sería esencial disponer de más estudios, cuantitativos y cualitativos, que los aborden. Sin duda, sería muy fructífera la colaboración entre distintos campos, concretamente entre la sociología del teatro y los estudios teatrales, para producir conocimiento en torno a la conexión que pudo darse en España durante los años más duros de la crisis entre nuevas prácticas culturales, movimientos sociales y la emergencia de nuevas formas teatrales. Una perspectiva comparada, que analizara la respuesta del teatro alternativo ante la crisis en distintos países, sería a su vez muy valiosa para tener una visión más amplia y transnacional de estos fenómenos.

En todo caso, pasada ya una década desde la inauguración de la multisala Microteatro por Dinero, podemos realizar una valoración provisional de la herencia que dejaron los Nuevos Formatos. Esperamos que futuras investigaciones, así como el propio desarrollo del teatro alternativo español, amplíen, maticen o corrijan lo que la distancia temporal y los estudios actuales nos permiten concluir en este momento.

La primera valoración que debería hacerse tiene un cariz ciertamente negativo. Numerosas voces sobre todo entre las nuevas generaciones de creadores $3 / 4$ han denunciado la precariedad a la que conducen los Nuevos Formatos Teatrales. Lejos de representar una oportunidad, argumentan dramaturgas como Diana Luque o Pilar Almansa, la tendencia a producir espectáculos de pequeño formato es un dramático reflejo de la escasez de medios que caracteriza a los creadores de nuestro país. Sin negar que 
puedan surgir interesantes experiencias escénicas, Diana Luque insiste en que el pequeño formato condena a la creación escénica a un teatro de pura "supervivencia" (2014: 39).

De hecho, en "Buscando modelos para el off", artículo publicado en 2017 en la Revista Godot, la dramaturga Pilar Almansa advertía de que la proliferación de pequeños espacios no debe ser vista como un síntoma de salud ni su éxito comercial tiene por qué implicar que el teatro llegue a nuevos públicos. Para ella, los rasgos que caracterizan la exhibición teatral madrileña son, de hecho, la atomización del espacio y del tiempo:

Un conglomerado de causas (más licenciados de escuelas oficiales y no oficiales, ausencia de mecanismos transparentes de acceso a espacios públicos, emprendimiento como mecanismo de visibilización del propio trabajo...) han hecho que la exhibición teatral madrileña se atomice en el espacio y el tiempo: en el espacio, por la proliferación de espacios de exhibición con aforos cada vez más reducidos; y en el tiempo, por la multiprogramación, al servicio del necesario sostenimiento económico de la sala (Almansa, 2017).

Según su análisis, este proceso en el que el aumento de la oferta y la atomización de la exhibición concurren se ha realizado de forma simultánea al descenso generalizado de asistentes a espectáculos en vivo. Así, siempre según Almansa, los creadores teatrales en realidad no habrían buscado nuevos públicos, sino que habrían tratado de reducir el riesgo de no tener público a través de un aumento de la oferta, una reducción del aforo y una disminución en la duración de la temporada. De este modo, aunque el aforo potencial del conjunto de los espacios aumenta, este mismo sufre un proceso de atomización en un contexto decreciente en términos globales. "El riesgo de no tener público, por lo tanto, se mantiene estable, aunque ahora hay muchos más sitios donde esa ausencia es posible" (Almansa, 2017).

En este sentido, parece que los esperanzados deseos de José Martret, creador de La Casa de la Portera que citábamos al comienzo de este artículo -recordemos que incidía en la necesidad de imaginar otros modos de ver, producir y distribuir teatro- se han acabado estrellando contra la realidad deficitaria de nuestro tejido cultural. En esta misma dirección, Almansa señala con excelente criterio que, aunque quisiéramos 
imitar modelos para el off como los que existen en Francia, Reino Unido o Estados Unidos, países en los que existe una escena alternativa menos precaria, sería imposible trasplantar a nuestro país dichos modelos, pues la realidad legislativa, fiscal, educativa y cultural no es comparable:

La solución no consiste solamente en aprobar una ley de mecenazgo, una intermitencia o un sistema de ayudas públicas solvente (sin por ello quitarle valor a su implantación). Esas medidas tendrán que convivir con un entramado fiscal y laboral concreto, unos planes educativos, una cultura empresarial... que no necesariamente se comportarán o transformarán de manera análoga a los de los referentes mencionados (Almansa, 2017).

Sea como sea, en las palabras de Almansa encontramos sugerido uno de los legados más positivos -aunque aún en vías de alcanzarse plenamente- que ha dejado la época de la crisis. Nos referimos a la implementación de una Ley de mecenazgo y de un Estatuto del Artista semejante al que existe en Francia, así como una Ley de sala alternativa como la que existe en Argentina, una medida de política cultural que sin duda ayudaría a espacios pequeños y poco convencionales a mantener sus puertas abiertas.

Y es que, una década más tarde, el balance de las salas no convencionales que han seguido con sus puertas abiertas es bastante desolador. De los tres espacios y formatos estudiados en este artículo, solo Microteatro por Dinero permanece abierto. La Casa de la Portera y los espacios específicamente escénicos que albergaron Teatro en Serie en sus siguientes montajes -La Trastienda (Sierpe, 2) y El Apartamento (Génova, 7)- hace tiempo que tuvieron que cerrar sus puertas. Como también cerraron otras salas emblemáticas, como por el ejemplo El sol de York (Arapiles, 16), Kubik Fabrik (Primitiva Gañán, 5) o La Pensión de las Pulgas (Huertas, 48). Así, aunque en un primer momento, sobre todo en torno a 2015, se produjo un auténtico boom de Nuevos Formatos y Espacios teatrales, los últimos años han sido testigo de un evidente reflujo (cfr. Luque, 2014: 39; Corroto, 2014).

En todo caso, hay un espacio teatral en Madrid cuya historia sobresale y hasta cierto punto contradice este escenario pesimista. Nos referimos al Teatro del Barrio (Zurita, 20), una de las salas surgidas al 
albur de la crisis que más visibilidad tiene en la actualidad (Boehm, 2018). La idea de abrir un teatro en la antigua sala Triángulo fue iniciativa de distintos profesionales de las artes escénicas -la cara más visible es el actor, dramaturgo y director Alberto San Juan-, quienes apostaron por crear una cooperativa cultural en diciembre de 2013. Tal y como podemos leer en su página web:

La voluntad con la que abrimos el Teatro del Barrio es abiertamente política: participar en el movimiento ciudadano que ya está construyendo otra forma de convivir.

Este teatro nace del hambre de realidad. La realidad tiene siempre algo maravilloso: por terrible que sea, puede ser transformada. Si se conoce. Y esta es la vocación del proyecto: saber qué está pasando aqui, por qué no nos gusta y por qué queremos cambiarlo. Este teatro pretende ser una asamblea permanente donde mirar juntos el mundo, para, juntos, imaginar otro donde la buena vida sea posible ${ }^{19}$.

El espíritu que se refleja en esta declaración de intenciones -todo un manifiesto artístico- es otra de las herencias que ha dejado la época de la crisis en el teatro independiente madrileño. Nos referimos a que, en los últimos años, se ha producido una repolitización del mismo y, también, su recuperación como herramienta para la participación ciudadana. El Teatro del Barrio - pero también otros espacios como la hoy desaparecida Kubik Fabrik de Usera- inciden en el teatro como asamblea, como lugar propicio para imaginar otras realidades y formas de vivir juntos. En esta misma línea hay que entender también otras iniciativas como Lavapiés Barrio de los Teatros, una red que aúna a catorce teatros ${ }^{20}$ ubicados en dicho barrio madrileño y que tiene como objetivo la colaboración entre ellos: "A la crisis económica, social y cultural que vivimos, nosotros oponemos un deseo, una aspiración, una voluntad. Y arriesgamos todas nuestras fuerzas en la búsqueda de una alternativa de creación y difusión del teatro basada

${ }^{19}$ Cf. https://www.teatrodelbarrio.com/what-i-do/ [20/05/2019].

${ }^{20}$ Forman parte de la red espacios alternativos como el Off de la Latina, Nuevo Teatro Fronterizo o El Umbral de Primavera, pero también espacios convencionales, como en CDN o La Casa encendida. 
en la dignidad" 21 .

Como vemos, es complejo decidir si el balance de la crisis en la creación teatral independiente es positivo o negativo. Por un lado, la precariedad y la falta de medios es evidente. Por otro, percibimos un ambiente más dinámico y abierto, caracterizado por la decidida voluntad de colaborar y seguir creando a pesar de las circunstancias. Solo el tiempo podrá ofrecernos los elementos de juicio que nos permitan valorar con más distancia las aportaciones que generaron los Nuevos Espacios y Formatos al desarrollo del teatro español. Una de las herencias más positivas que podrían darse sería haber servido como semilleros -invernaderos culturales- para los creadores jóvenes. Quizás, cuando pasen los años, elogiemos a estos espacios y formatos teatrales por haber servido de cantera a los actores, dramaturgos y directores del siglo XXI.

\section{REFERENCIAS BIBLIOGRÁFICAS}

ALMANSA, P. (2017). "Buscando modelos para el off". Revista Godot, 21 de marzo. Disponible en línea: http://www.revistagodot.com/ buscando-modelos-para-el-off/ [20/03/2019].

ALONSO DE SANTOS, J.-L. (1989). "Principio y fin del teatro independiente". Campus 31.

BOEHM, S. (2018). "Popular Theatre as Space and Symbol of the Spanish Democratic Revolution", Bulletin of Hispanic Studies 95, 1085 1106.

BROOK, P. (2010). La puerta abierta. Barcelona: Alba Editorial. (2012). El espacio vacío. Barcelona: Península.

CAMERON, B. (2014). "Spain in Crisis: 15-M and the Culture of Indignation". Journal of Spanish Cultural Studies 15.1-2, 1-11.

CORNAGO BERNAL, Ó. (1999). La vanguardia teatral en España (1965-1975). Del ritual al juego. Madrid: Visor Libros.

CORROTO, P. (2014). "La autogestión como trampa". Eldiario.es, 7 de enero. Diponible en línea: https://www.eldiario.es/cultura/ autogestion-trampa_0_211729000.html [12/03/2019].

(2015). "La burbuja del off madrileño". Eldiario.es, 25 de marzo.

21 http://www.lavapiesbarriodeteatros.es/ [20/05/2019]. 
Disponible en línea: https://www.eldiario.es/cultura/teatro/ burbuja-teatro-off-madrileno_0_370263233.html [12/03/2019].

DANAN, J. (2013). Entre théâtre et performance: la question du texte. Arles: Actes Sud.

FEINBERG, M. (2014). "Don Juan Tenorio in the Campo de Cebada: Restaging Urban Space after 15-M". Journal of Spanish Cultural Studies 15.1-2, 43-59.

FERNÁNDEZ INSUELA, A. (1975). "Notas sobre el teatro independiente español". Archivum. Revista de la Facultad de Filología 25, 303322.

FERNÁNDEZ SANTOS, E. (2013). "El teatro alternativo llama a su puerta". El País, 30 de diciembre. Disponible en línea: https:// elpais.com/cultura/2013/12/29/actualidad/1388346871_209123. html [20/03/2019].

FISCHER-LICHTE, E. (2011). Estética de lo performativo. Madrid: Abada Editores.

GARCÍA, R. (2013). "El sector del teatro se desangra por el 'devastador' aumento del IVA". El País, 21 de marzo. Disponible en línea: https:// elpais.com/cultura/2013/03/21/actualidad/1363872815_952612. html [20/03/201].

HAYLES, N. K. (2007). "Hyper and Deep Attention: The Generational Divide in Cognitive Modes". Profession, 187-199.

HUERTA CALVO, J. (dir.) (2008). Historia del teatro breve en España. Madrid / Frankfurt: Iberoamericana.

LEHMANN, H-T. (2012). "Réflexions sur le spectateur dans le théâtre pré- et postdramatique". Critical Stages 7, 1-4.

LILlO, M. (2014). "El sol de York no calentó lo bastante". El País, 28 de julio. Disponible en línea: https://elpais.com/ccaa/2014/07/29/ madrid/1406660294_751998.html [20/03/2019].

LÓPEZ DE ARRIBA, L. (2013). Días como estos. Capitulos I-IV [obra inédita].

(2017). "Nuevos formatos teatrales. Microteatro y Teatro en serie, abriendo caminos". Don Galán 7. Disponible en línea: http:// teatro.es/contenidos/donGalan/donGalanNum 7/sumario.php [12/01/2019].

LUQUE, D. (2014). "Reflexiones sobre la dramaturgia emergente en España: visibilidad y supervivencia en el contexto de las crisis 
actuales (más una nómina de jóvenes dramaturgos españoles)". En Creadores jóvenes en el ámbito teatral $(20+13=33)$, J. Romera Castillo (ed.), 34-53. Madrid: Verbum.

MOLINA, J. (2013). "Milagro teatral en pequeño formato". El País, 7 de mayo. Disponible en línea: http://elpais.com/elpais/2013/05/03/ eps/1367597433_981805.html[12/03/2019].

MOÏSI, D. (2017). Geopolítica de las series o el triunfo global del miedo. Madrid: Errata Naturae.

MORENO, F.-A. (ed.)(2015). Yo soymás de series. 60 series que cambiaron la historia de la televisión. Madrid: Esdrújula ediciones.

NEVEUX, O. (2013). "Intervenir dans la crise. Le théâtre politique à l'heure de la crise". Seminario inédito organizado por el equipo de investigación C.H.E.R. (Culture et Histoire dans l'Espace Roman) el 8 de noviembre de 2013 en el marco del programa "Hybris et catastrophe: les arts de la scène en Europe face à la crise", Maison Interuniversitaire des Sciences de 1'Homme-Alsace (Universidad de Estrasburgo).

ORDÓÑEZ, M. (2014). “Teatros del barrio". El País, 16 de junio. Disponible en línea: https://elpais.com/cultura/2014/06/16/ babelia/1402935863_267256.html [25/02/2019].

PEARSON, M. (2010). Site-Specific Performance. London: Palgrave MacMillan.

PEIRÓ, P. (2013). "La primavera de los teatros". El País, 15 de marzo. Disponible en línea: https://elpais.com/ccaa/2013/03/14/ madrid/1363295480_358825.html [25/03/2019].

PÉREZ-RASILLA, E. (2008). "El arte escénico". En Historia del teatro breve en España, Javier Huerta Calvo (dir.), 947-968. Madrid / Frankfurt: Iberoamericana.

ROMERA CASTILLO, J. (ed). (2014). Creadores jóvenes en el ámbito teatral $(20+13=33)$. Madrid: Verbum.

SANTOLARIA, C. (1997). "El teatro no profesional en la década de los 60: el camino hacia el teatro independiente". Revista de Estudios Teatrales 11, 193-209.

TREMLETT, G. (2013). "Spain's microtheatres provide lifeline for actors as public subsides dry up". The Guardian, 28 de febrero. Disponible en línea: http://www.theguardian.com/world/2013/feb/28/spainausterity-arts-funding-microtheatres [12/03/2019]. 
UBERSFELD, A. (1996). Lire le théâtre II. L'école du spectateur. Paris: Belin.

Recibido el 28 de marzo de 2019.

Aceptado el 6 de mayo de 2019. 